\title{
Comparison and analysis of magnetic noise and drive losses using different PWM methods (1165)
}

\author{
Torbjörn Trosten ${ }^{1} \quad$ Henrik Mosskull $^{1} \quad$ Daniel Jansson $^{1} \quad$ Maher Azaza $^{2} \quad$ Erik Dahlquist $^{2}$ \\ ${ }^{1}$ Bombardier Transportation, Vasteras, Sweden \\ ${ }^{2}$ Mälardalens University, Vasteras, Sweden
}

\begin{abstract}
In this paper several discontinuous pulse width modulation methods (DPWM) are compared with space-vector pulse width modulation (SV-PWM) method. The comparisons are done based on measurements of motor magnetic noise and total drive losses for inverter switching frequencies from $500 \mathrm{~Hz}$ to $4000 \mathrm{~Hz}$. It is concluded that using SV-PWM it is possible to reach lower magnetic noise on the traction motor without increasing the total losses significantly.
\end{abstract}

Keywords: $\quad$ DPWM, SVM, magnetic noise, inverter losses, harmonic losses traction, Metro

\section{Introduction}

The typical voltage source inverter (VSI) used in a variable speed drive (VSD) use a pulse width modulation (PWM) method to generate the required motor phase voltages. Depending on the application and requirements, different control algorithms and different PWM methods are used. Typical control methods are direct torque control (DTC), direct self-control (DSC), indirect self-control (ISC) and field-oriented control (FOC). All these control methods rely on the control of certain electrical machine quantities by controlling the switching states of the VSI, in doing so the control method and PWM method can become intervened and it can become difficult to describe the PWM method as separate from the control method. However, during ideal steady state conditions the control method and PWM method can be characterized separately. Some important PWM methods are sinusoidal PWM (SPWM) (Schonung and Stemmler, 1964), space vector PWM (SV-PWM) (Van Der Broeck, et al., 1986) and Discontinuous PWM (DPWM) (Depenbrock, 1977). The main difference between S-PWM or SVPWM and the DPWM methods is that the DPWM methods clamp one of the phases at certain angles. The purpose with the clamp is to reduce the inverter switching losses of the clamped phase, the reduction of switching losses depends on the phase current magnitude during the clamp. In (Hava et al., 1998) it is reported that inverter switching losses are significantly reduced using DPWM methods. In (Binojkumar et al., 2016) it is reported that the inverter related switching noise is lower using DPWM methods. In (Andersson and Thiringer, 2017), the inverter losses and magnetic noise from the motor was investigated using an experimental setup, a reduction in inverter losses was noted. However, the motor magnetic noise did not improve.

In this paper, several DPWM methods are compared experimentally with SV-PWM in terms of motor magnetic noise and both inverter and motor harmonic losses. In order to further understand the relations between motor magnetic noise, losses and PWM methods measurements are performed using switching frequencies between $500 \mathrm{~Hz}$ and $4000 \mathrm{~Hz}$.

Section 2 describes the characteristics of the tested PWM methods and Section 3 presents data from loss and noise tests. Section 4 present an analysis of the noise measurements, Section 5 summarizes and concludes.

\section{Characteristics of tested PWM methods}

The different modulation methods are commonly described, and easily implemented using their characteristic duty ratio (Hava et al., 1998). In Figure 1 , the characteristic duty-ratio for SV-PWM is shown side by side with the characteristic duty ratio of DPWM1. At the times, where duty ratio is 0 or 1 , the
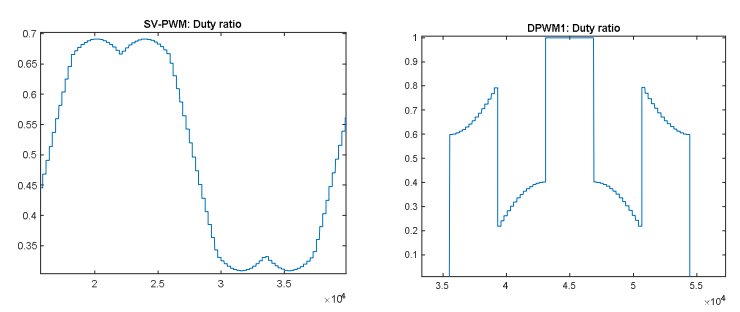

Figure 1. Duty ratio of SV-PWM (left) and DPWM1 (right) method.

phase is clamped, i.e. not switching. In terms of voltage harmonics, the main difference between SV-PWM and DPWM lies in the amplitude of the main switching harmonics. For the SV-PWM method the largest voltage and current harmonics occurs at twice the switching frequency and four times the switching frequency. The discontinuous methods produce a harmonic spectrum where the first harmonic is largest, the second is the 
second largest and so on. This is illustrated in Figures 2 to 4 , where the measured phase voltage spectrums for SV-PWM and two of the tested DPWM methods are plotted.

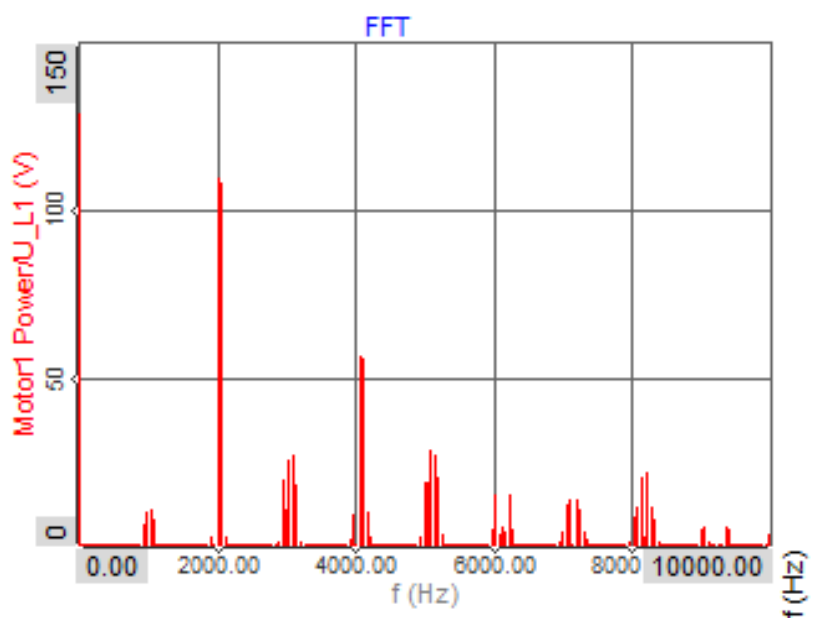

Figure 2. Measured phase voltage spectrum of SV-PWM operating at $1022 \mathrm{~Hz}$.

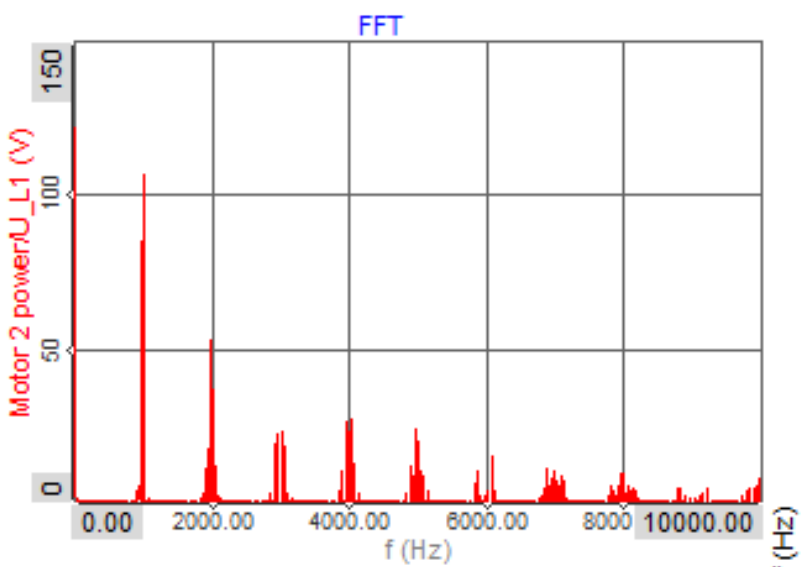

Figure 3. Measured phase voltage spectrum for DPWM Max.

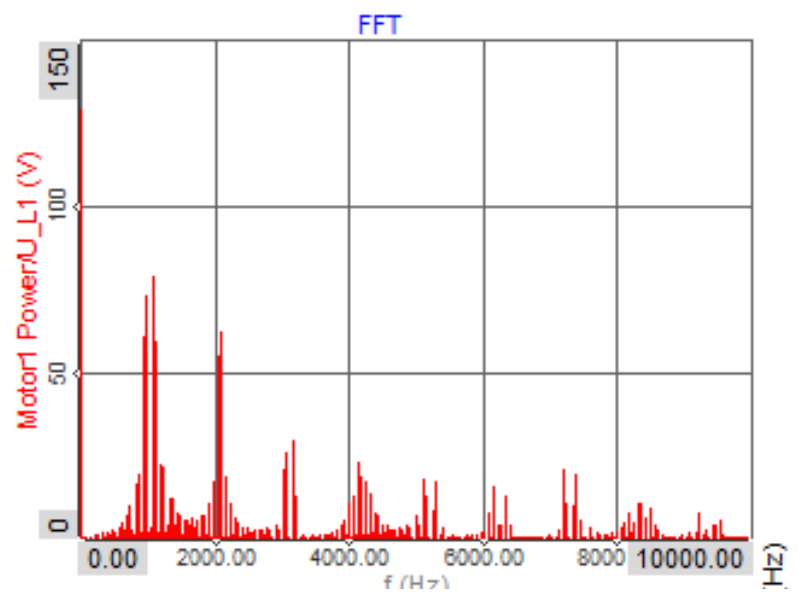

Figure 4. Measured phase voltage spectrum of DPWM1 operating at $1000 \mathrm{~Hz}$.

\section{Measurements}

\subsection{Loss measurements}

The traction motor is operated at $627 \mathrm{rpm}$ and 1017 $\mathrm{Nm}$, corresponding to full tractive effort at a speed of 15 $\mathrm{km} / \mathrm{h}$ for typical metro train. Losses in both inverter and motor are measured. The inverter losses are reduced for the tested discontinuous PWM methods; however, the motor harmonic losses are increased. This is seen in Figures 5 and 6.

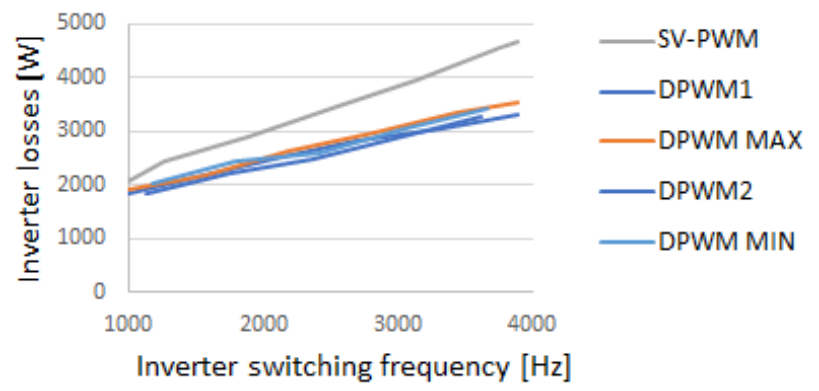

Figure 5. Measured losses in the inverter using different PWM methods.

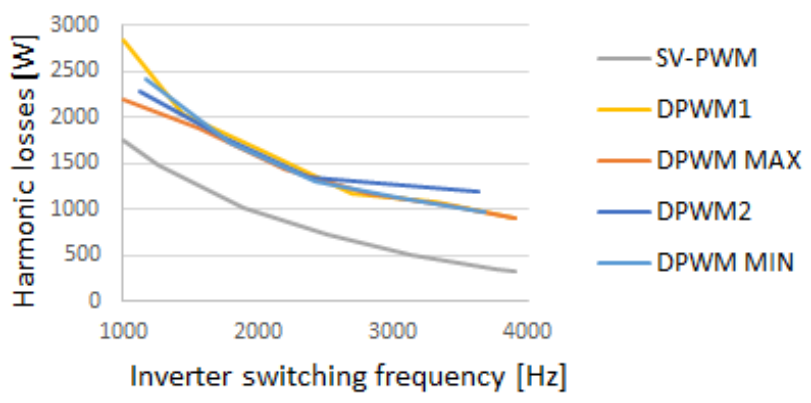

Figure 6. Measured motor harmonic losses using different PWM methods.

A comparison of total switching related losses, inverter and motor harmonic losses is shown Figure 7.

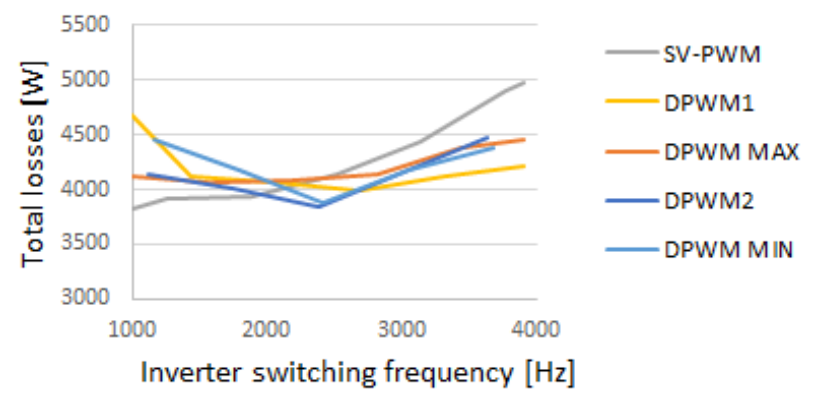

Figure 7. Measured inverter and motor harmonic losses using different PWM methods. 


\subsection{Noise measurements}

In order to investigate the pulse patterns more in detail, the magnetic noise from the motor is measured using different inverter switching frequencies and pulse patterns. For each pulse pattern the inverter switching frequency is changed in steps of approximately $110 \mathrm{~Hz}$. Each frequency is kept for 5 seconds, so that the average sound pressure level (SPL) can be measured. The measurements are done at no-load since at full load the Silicon ( $\mathrm{Si}$ ) based IGBTs of the inverter could overheat during such a test. A comparison of measured sound pressure level (SPL) using different PWM methods and switching frequencies is presented in Figure 8.

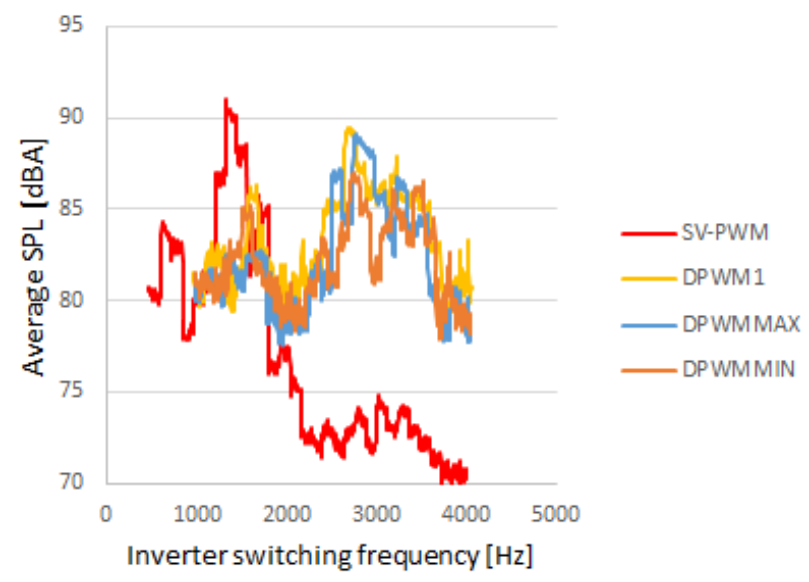

Figure 8. Measured SPL for different pulse patterns and inverter switching frequencies.

From the measurement it is seen that SPL varies significantly with the switching frequency and that relatively small changes in switching frequency can result in large changes in noise. It is also seen that above $1.8 \mathrm{kHz}, \mathrm{SV}-\mathrm{PWM}$ offers the lowest magnetic noise.

\section{Analysis of noise measurements}

In order to understand the behavior of the magnetic noise more in detail, the raw data from a single microphone, which was used during the tests, is analyzed more in detail. An FFT is performed and the amplitude and frequency of the two harmonics with largest amplitude are plotted in Figure 9. The largest amplitudes are recorded for frequencies between $2 \mathrm{kHz}$ and $4 \mathrm{kHz}$ (Figure 9). This behavior can be explained by considering that the structural mechanical resonance modes 0 and 4 , of a traction motor this size, is typically located between $2 \mathrm{kHz}$ and $4 \mathrm{kHz}$. Considering the relationship between harmonic amplitudes for SVPWM and DPWM pulse pattern, one can explain the behavior in figure 9. The SV-PWM method generate the largest voltage harmonics at twice the switching frequency. The highest magnetic noise appears at roughly $1500 \mathrm{~Hz}$ switching frequency. The DPWM methods, where the first harmonic is the largest, generate the highest noise for switching frequencies around $3000 \mathrm{~Hz}$ as seen in Figure 8.

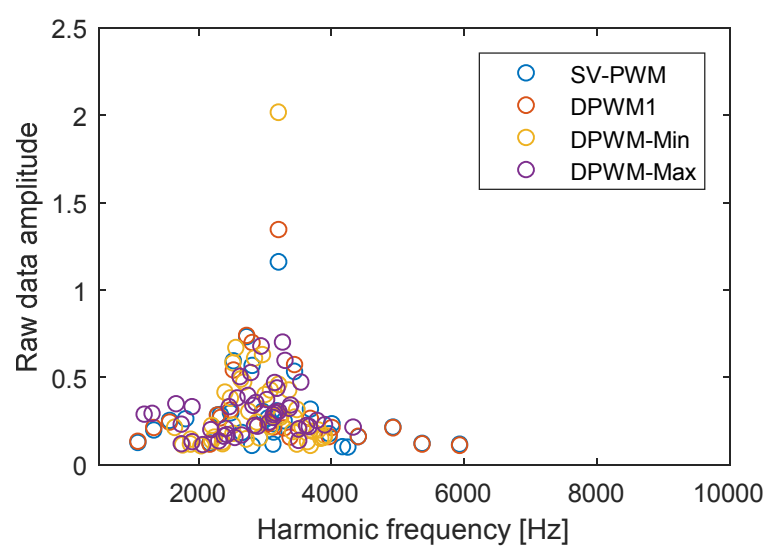

Figure 9. Raw amplitude and frequency of two largest harmonics for all noise tests.

In order to further investigate, if the measured magnetic noise is mainly related to the frequency of the main voltage harmonics. The measured noise using SVPWM between $500-2000 \mathrm{~Hz}$ is frequency shifted into $1000-4000 \mathrm{~Hz}$ and plotted together with the noise measurement from DPWM1. The result from the calculation is shown in Figure 10, the general behavior in the noise measurement using DPWM1 maps well with the noise measurement using SV-PWM using half the switching frequency. Indicating that it is the frequency of the main harmonics which is relevant for the magnetic noise.

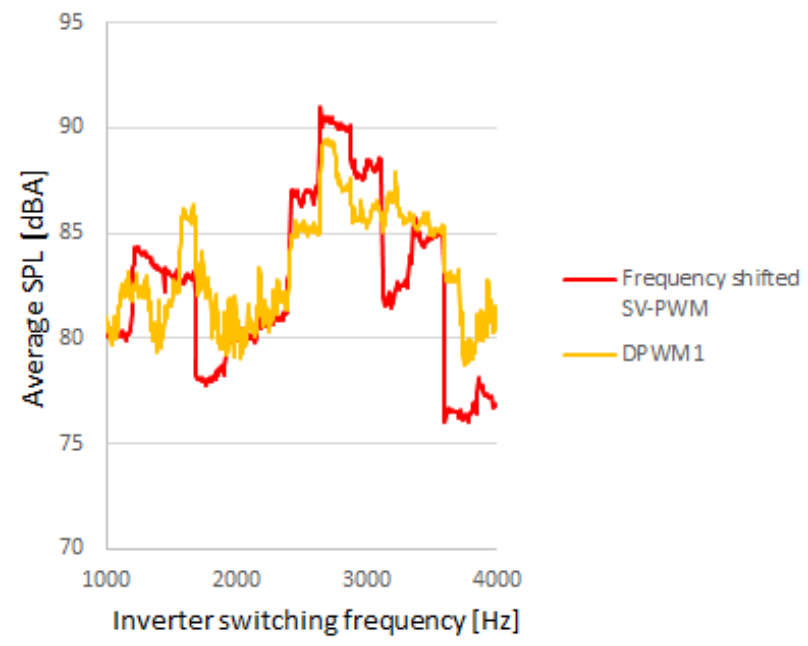

Figure 10. comparison of frequency shifted SV-PWM and DPWM1 noise.

\section{Conclusions}

The comparisons and analysis on loss and noise measurements for SV-PWM and DPWM methods 
show, that the magnetic noise using PWM methods can be understood by considering the resonance frequencies of the motor and the frequencies of the main voltage harmonics, generated by the PWM method. A more indepth analysis reveals that in terms of noise, the DPWM methods produce similar results as an SV-PWM, operating at half the switching frequency. The measurements further show that SV-PWM operated at $2 \mathrm{kHz}$ switching frequency generate both low losses and low noise for the tested traction motor.

\section{References}

A. Andersson and T. Thiringer. Experimental determination of inverter losses and sound consequences of using DPWM in an HEV. In 2017 IEEE Applied Power Electronics Conference and Exposition (APEC), Tampa, FL, pages 1382-1388, 2017.

A.C. Binojkumar, B. Saritha and G. Narayanan, Experimental comparison of Conventional and Bus-Clamping PWM Methods Based on Electrical and Acoustic Noise Spectra of Induction Motor Drives. IEEE Transactions on Industry Applications, 52(5):4061-4073, Sept.-Oct. 2016.

H. Van Der Broeck, H. Skudelny, and G. Stanke. Analysis and realization of a pulse width modulator based on voltage space vectors. In Conf. Rec. IEEE-IAS Annu. Meeting, pages 244-251, 1986.

M. Depenbrock. Pulse width control of a 3-phase inverter with nonsinusoidal phase voltages. In Conf. Rec. IEEE Int. Semiconductor Power Conversion Conf., pages 399403, 1977.

A. M. Hava, R. J. Kerkman, and T. A. Lipo. A highperformance generalized discontinuous PWM algorithm. IEEE Transactions on Industry Applications, 34(5): 1059-1071, 1998. doi: 10.1109/28.720446.

A. Schonung and H. Stemmler. Static frequency changers with subharmonic control in conjunction with reversible variable-speed ac drives, Brown-Boveri Rev., pages 555577, 1964. 